\title{
'Monogamous' vole in love-rat shock
}

By traditionalist standards, prairie-vole couples may enjoy the ideal relationship: the rodents form lifelong partnerships - a highly unusual practice in mammals. Males help raise the children; females help build the nest. As for their sex life, let's just say it far exceeds the efforts required for procreation.

But the respectable public behaviour of North American prairie voles (Microtus ochrogaster) may hide a bed-hopping double life. Paternity tests published last week indicate that the animals touted as paragons of monogamy frequently cheat on their partners (A. G. Ophir et al. Anim. Behav. doi:10.1016/ j.anbehav.2007.09.022; 2008). "Ironically", the study's authors conclude, "the dissociation of social and sexual fidelity leads us to suggest that prairie voles are even better models of human attachment than has been appreciated."

Studies on prairie voles have led scientists to look at the role of hormones such as vasopressin and oxytocin in strengthening human relationships. Revelations of infidelity in the creatures will not change the significance of that research, but may make the voles a little less popular among political agitators for sexual abstinence. (Eric Keroack, who headed a government family-planning committee in the United States, even used the monogamous voles as evidence to support his view that people who have extramarital sex damage their oxytocin signalling mechanisms.)

Over the past few decades researchers have learned to distinguish between 'social monogamy' - in which a pair lives and tends their young together - and 'sexual monogamy', in which a couple mates exclusively with each other. "You may have a partner you come home to every night," says Alexander Ophir, a biologist at the University of Florida in Gainesville, "but that's not necessarily the one that you're mating with."
Ophir and his colleagues found that infidelity had no effect on reproductive success: a cheating vole was just as likely to reproduce as a faithful one, so long as the cheater maintained a socially monogamous relationship. Sue Carter, a biologist at the University of Illinois at Chicago, says that these findings highlight the importance of social bonding. "Humans want to believe in sexual monogamy," says Carter. That focus may have distracted people from the relative importance of social monogamy, she says.

Carter has observed philandering voles in her own lab, and notes that the infidelity did not disrupt pre-existing partnerships. When a female initiates contact with an outside male, for example, the relationship remains strictly sexual. "She mated with him," says Carter, "and then she attacked him, ran him off and went back to her established partner."

Heidi Ledford 